\title{
Typing of Aeromonas spp. by numerical analysis of immunoblotted SDS-PAGE gels
}

\author{
ROHINTON MULLA and SALLY MILLERSHIP* \\ Department of Bacteriology, Royal Postgraduate Medical School, Hammersmith Hospital, Du Cane Road, \\ London W12 ONN
}

\begin{abstract}
Summary. One hundred and three isolates of Aeromonas spp., collected from both environmental sources and patients, were examined by SDS-PAGE of whole cells followed by immunoblotting with polyclonal rabbit antiserum raised against whole cells of $A$. sobria. All isolates were typable, yielding 15-20 well separated bands. Reproducibility of the technique was good and discrimination excellent, yielding 30 types amongst 103 isolates. Immunoblot type was not related to biochemical phenotype. Attempts to correlate immunoblot type with serotype were unsuccessful because only $42 \%$ of the strains tested could be serotyped.
\end{abstract}

\section{Introduction}

Mesophilic members of the genus Aeromonas have been recognised as human pathogens for more than 30 years. ${ }^{1}$ Aeromonads have been isolated from blood cultures in immunosuppressed and cirrhotic patients. ${ }^{2}$ Less commonly, cases of cellulitis and wound infections, ${ }^{3}$ meningitis, ${ }^{4}$ otitis, peritonitis and endocarditis have been recorded ${ }^{1}$ and hospital outbreaks have been described..$^{5-7}$ These organisms have also been recognised as gastrointestinal pathogens in some studies. 8-10 $^{-10}$

Therefore, there is a need for a typing system that will help in understanding the epidemiology of this organism. Methods so far attempted include serotyping, ${ }^{11}$ haemagglutination patterns, ${ }^{12,13}$ enzyme electrophoresis ${ }^{7}$ and whole-cell protein fingerprints. ${ }^{14}$ Serotyping has not proved very successful because many strains are not typable with currently available sera. ${ }^{11}$ Haemagglutination suffers from poor reproducibility. ${ }^{13}$ Whole-cell protein electrophoresis has been used ${ }^{\mathbf{1 4}}$ but has the disadvantage that a large number of bands (up to 60) needs to be analysed.

A further difficulty in the study of the epidemiology of the aeromonads is the considerable confusion surrounding their taxonomy. Three phenospecies, A. caviae, A. sobria and A. hydrophila, are generally recognised. ${ }^{15}$ However, a number of newer phenotypes, including some within the recognised groups ${ }^{16-18}$ and some completely new ones, ${ }^{19}$ have now been described.

Therefore, we examined immunoblotting with regard to both conventional and newer phenotypes as a means of discriminating between strains of Aeromonas

Received 8 Sept. 1992; revised version accepted 21 March 1993.

* Correspondence should be sent to Dr S. Millership. spp. When this method has been applied to other microbial genera, all strains have been typable, ${ }^{20-22}$ and reproducible electrophoretic fingerprints have been obtained, with relatively few bands which are easy to interpret.

\section{Materials and methods}

\section{Bacterial strains}

A total of 103 isolates of Aeromonas spp. collected from environmental sources and patients was examined (table), including six reference strains $-A$. caviae ATCC 13136, A. schubertii ATCC 43700, $A$. veronii ATCC 35622, A. media ATCC 33907, A. sobria ATCC 9071 and $A$. hydrophila ATCC 7965. Isolates were maintained for short periods on nutrient-agar slopes and for long term in liquid nitrogen. All strains were checked for their positive oxidase reaction, failure to grow in nutrient broth containing $\mathrm{NaCl} 6 \% \mathrm{w} / \mathrm{v}$, growth in the presence of a disk containing $150 \mu \mathrm{g}$ of O/129 (2,4 diamino-6,7-di-isopropyl pteridine), and reactions in an API 20E gallery (API systems, La Balme les Grottes, France). Further tests to assign strains to one of the phenospecies, hydrophila, caviae or sobria, were as previously described: $:^{23}$ fermentation of lactose on MacConkey agar, growth at $42^{\circ} \mathrm{C}$ on horse-blood agar (HBA), haemolysis on HBA, fermentation of glucose with production of gas, fermentation of salicin and arabinose, acetylmethylcarbinol production (Voges-Proskauer) by the Barrit method, ${ }^{24}$ elastase production, ${ }^{25}$ aesculin hydrolysis, lysine decarboxylase by Moeller's method, ${ }^{26}$ gluconate oxidation and $\mathrm{H}_{2} \mathrm{~S}$ production.

Further tests were also performed to identify newly described phenospecies. ${ }^{16,19,27}$ Where required, tests 
for cellobiose and mannitol fermentation and decarboxylation of arginine and ornithine were performed. Reactions in the API 20E trays for indole production and sucrose fermentation were noted and the minimum inhibitory concentration (MIC) of ampicillin was determined. An MIC of $\leqslant 2 \mathrm{mg} / \mathrm{L}$ was regarded as indicating sensitivity.

\section{Sample preparation}

Cell-free extracts of whole-cell proteins were prepared from cultures grown overnight on HBA. Five colonies were suspended in $1 \mathrm{ml}$ of sodium dodecyl sulphate (SDS) $1 \% \mathrm{w} / \mathrm{v}$ and boiled for $3 \mathrm{~min}$. The samples were allowed to cool to room temperature and centrifuged at $12000 \mathrm{rpm}$ for $10 \mathrm{~min}$. The clear supernate was removed and the protein concentration was measured by the method of Lowry $^{28}$ and standardised to $100 \mathrm{mg} / \mathrm{L}$ by appropriate dilution in sample buffer. The effect of different media on the expression of proteins was examined by culturing selected strains on MacConkey agar, cystine lactose electrolyte deficient (CLED) agar and deoxycholate citrate agar (DCA). Seven strains (three $A$. caviae, three $A$. hydrophila and one $A$. sobria), were serially subcultured on HBA plates at weekly intervals for 4 months. Five protein preparations of each strain were made at weekly intervals for 4 months.

\section{Production of antibody}

Antibodies to whole-cell proteins of $A$. sobria $\mathrm{P} 0027$ were raised in two female half-lop rabbits: $0.5 \mathrm{ml}$ of a 1:1 mixture of Freund's complete adjuvant and a cell-free extract of lysed bacteria, was injected subcutaneously at a single site on three occasions 10 days apart. Two subsequent booster injections without adjuvant were administered at intervals of 15 days and the animals were test bled. Serum was collected at 2-week intervals. Both animals were given booster injections every 3-4 weeks. All serum samples were pooled and stored at $-20^{\circ} \mathrm{C}$ in small volumes.

\section{Electrophoresis and blotting}

An acrylamide gel was used in a discontinuous Laemmli system, ${ }^{29}$ with stacking and resolving gels containing acrylamide $3 \% \mathrm{w} / \mathrm{v}$ and $12.5 \% \mathrm{w} / \mathrm{v}$ respectively. A $25-\mu$ l volume of sample was loaded on to each track. Biotinylated SDS mol. wt markers (Sigma) of 97400, 58100, 39800, 29000 and $14000 \mathrm{Da}$ were used. Gels were run at a constant current of $14 \mathrm{~mA}$ initially for stacking gel and then at $20 \mathrm{~mA}$ when the tracking dye entered the resolving gel. The electrophoresed proteins were transferred to a nitrocellulose membrane $(0.45-\mu \mathrm{m}$ pore size; Sigma) by capillary blotting overnight in blotting buffer $(0 \cdot 15 \mathrm{M}$ glycine, $0.25 \mathrm{M}$ Tris base in methanol $20 \% \mathrm{w} / \mathrm{v}$, $\mathrm{pH} 8 \cdot 3$ ). Membranes were transferred to a bath of fat- free milk powder $2.5 \% \mathrm{w} / \mathrm{v}$ in Tris buffer plus polyoxyethylene sorbitan monolaurate (Tween 20) $0 \cdot 3 \% \mathrm{v} / \mathrm{v}, \mathrm{pH} 7 \cdot 6$. The blots were then incubated sequentially with rabbit antiserum (diluted 1 in 20) for $2 \mathrm{~h}$, biotinylated (whole) donkey anti-rabbit antibody (Amersham) for $90 \mathrm{~min}$ and streptavidin-biotinylated horseradish peroxidase complex (Amersham) for $90 \mathrm{~min}$. Membranes were washed three times in a solution of fat-free milk powder $0.05 \% \mathrm{w} / \mathrm{v}$ in Tris buffer plus Tween $200.3 \% \mathrm{v} / \mathrm{v}$ after each stage. The blots were visualised with 4-carboxy 1-naphthol (4CIN; Sigma) $3 \mathrm{mg} / \mathrm{ml}$ in methanol and $\mathrm{H}_{2} \mathrm{O}_{2} 0 \cdot 05 \mathrm{w} / \mathrm{v}$ in phosphate-buffered saline, $\mathrm{pH}$ 7.0. The reaction was stopped by transferring the blot to distilled water.

\section{Analysis of gels}

The apparatus and analysis are described in detail elsewhere. ${ }^{30}$ Briefly, a high resolution image was scanned into an IBM PC compatible computer via a video camera (Model 90, with $55 \mathrm{~mm}$ lens and Hoya HA50 infra-red filter; Datacopy Corp., 1215 Terra Bella Ave, Mountain View, CA 94043, USA). The image $(1728 \times 2240$ pixels on a 256 shade grey scale) was then processed in a computerised program that located each lane and scanned its length to produce a densitometric trace corrected for background absorption and averaged across the lane width. The band positions in all lanes were also corrected for gel-to-gel variation in the positions of bands in the mol. wt standard tracks, run as controls on each gel.

These density scans (fig. 3) represented stained bands as absorption peaks along a scale representing their position along the gel corrected for gel-to-gel variations in mobility. Intense bands had high absorption values. A similarity coefficient was calculated by Fourier correlation ${ }^{14}$ for every pair of lanes. The matrix of similarities was used to construct the dendrogram shown in fig. 2, with a customised program for a sum of squares agglomerative algorithm. ${ }^{31}$

\section{Serology}

Thirty-six wild strains of Aeromonas spp. were sent to the Division of Enteric Pathogens, Central Public Health Laboratory, Colindale, London for confirmation of identity and serotyping.

\section{Results}

\section{Species identification}

Among the wild strains there were 53 isolates of A. caviae including four clusters of isolates from the same source and 26 single strains; 21 isolates of $A$. hydrophila including five clusters and nine single strains; and 15 single isolates of $A$. sobria. There were 18 isolates from patients and 34 food and environ- 


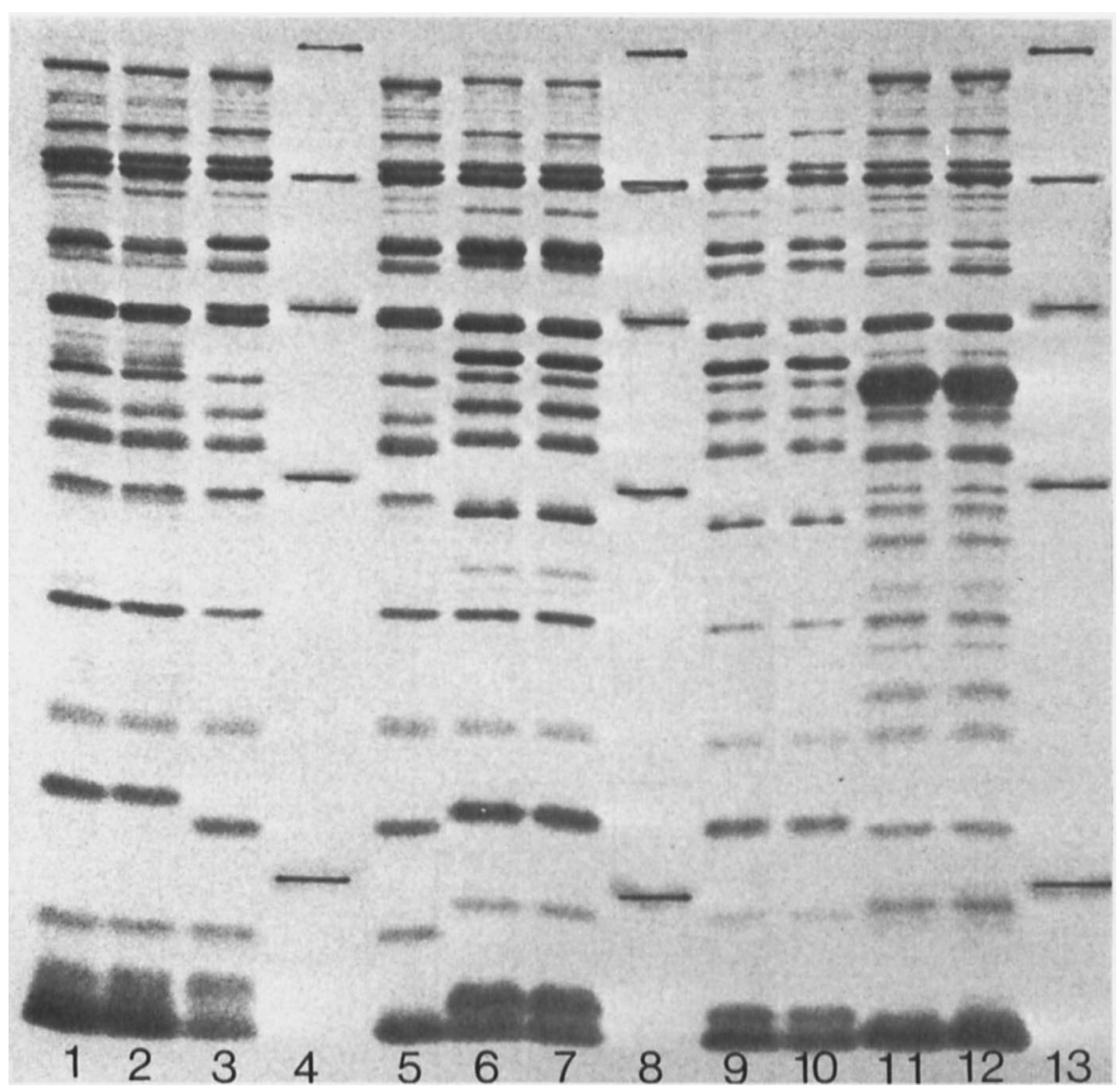

Fig. 1. Immunoblot of five Aeromonas strains. Tracks 1 and 2, strain E0089 (A. hydrophila); 3 and 5, strain E0087 (A. hydrophila); 6 and 7 , strain P0042 (A. caviae); 9 and 10, strain P0029 (A. caviae); 11 and 12, strain P0027 (A. sobria). Tracks 4, 8 and 13 show mol. wt markers of sizes $97400,58100,39800,29000$ and $14000 \mathrm{Da}$.

mental isolates of $A$. caviae, five clinical and 16 food and environmental isolates of $A$. hydrophila, and 11 clinical and three environmental isolates of $A$. sobria. Eight isolates could not be identified with any recognised, named group. Additional tests for newly described phenospecies did not reveal any isolates corresponding to the description of $A$. schubertii, A. veronii or A. trota.

All strains were typable by SDS-PAGE and immunoblotting, giving fingerprints with 15-20 well separated bands. Representative banding patterns of five Aeromonas strains are shown in fig. 1.

\section{Immunoblot typing}

Variation due to differences in staining, band width and residual variation in band position was investigated. Pairs of tracks derived from the same batch of sample and electrophoresed on the same and different gels were compared. Similarity coefficients for 68 replicate pairs analysed on the same gel showed a mean within-pair similarity of 94(SD4) \%. By contrast, comparison of 86 replicate pairs analysed on different gels gave a mean within-pair similarity of 83 (SD6)\%. Clearly, between-gel variation reduced replicate similarities by $10 \%$ and it seemed reasonable, therefore, to correct all within-gel similarities by a factor of $0 \cdot 9$, to allow direct comparison of within- and between-gel derived similarities in the calculation of the dendrogram (fig. 2).

Discrimination was also investigated. Comparison of pairs of strains of the same phenotype but epidemiologically distinct origin showed mean withinpair similarities of $55 \%$ for 87 within-gel pairs, and $43 \%$ for 87 between-gel pairs; SDs were larger for these heterologous comparisons at $17 \%$ and $14 \%$, respectively.

On the basis of these means and SDs, isolates showing similarities $>91 \%$ (within-gel comparison) or $76 \%$ (between-gel comparison) were regarded as indistinguishable. Isolates showing similarities $<75 \%$ (within-gel comparison) or $<65 \%$ (between-gel comparison) were regarded as distinct. This left a range of $91-75 \%$ (within-gel comparison) or $76-65 \%$ (between-gel comparison) within which results were regarded as equivocal. Despite the width of this range only $10 \%$ of isolate comparisons proved equivocal.

\section{Reproducibility}

Protein preparations of each of the five strains made at intervals throughout the 4 months showed that banding patterns did not alter after repeated subculture; 91 between-gel comparisons of pairs of 


\section{Reference and replicate strains \\ No. of Immunoblot \\ OTUs group}

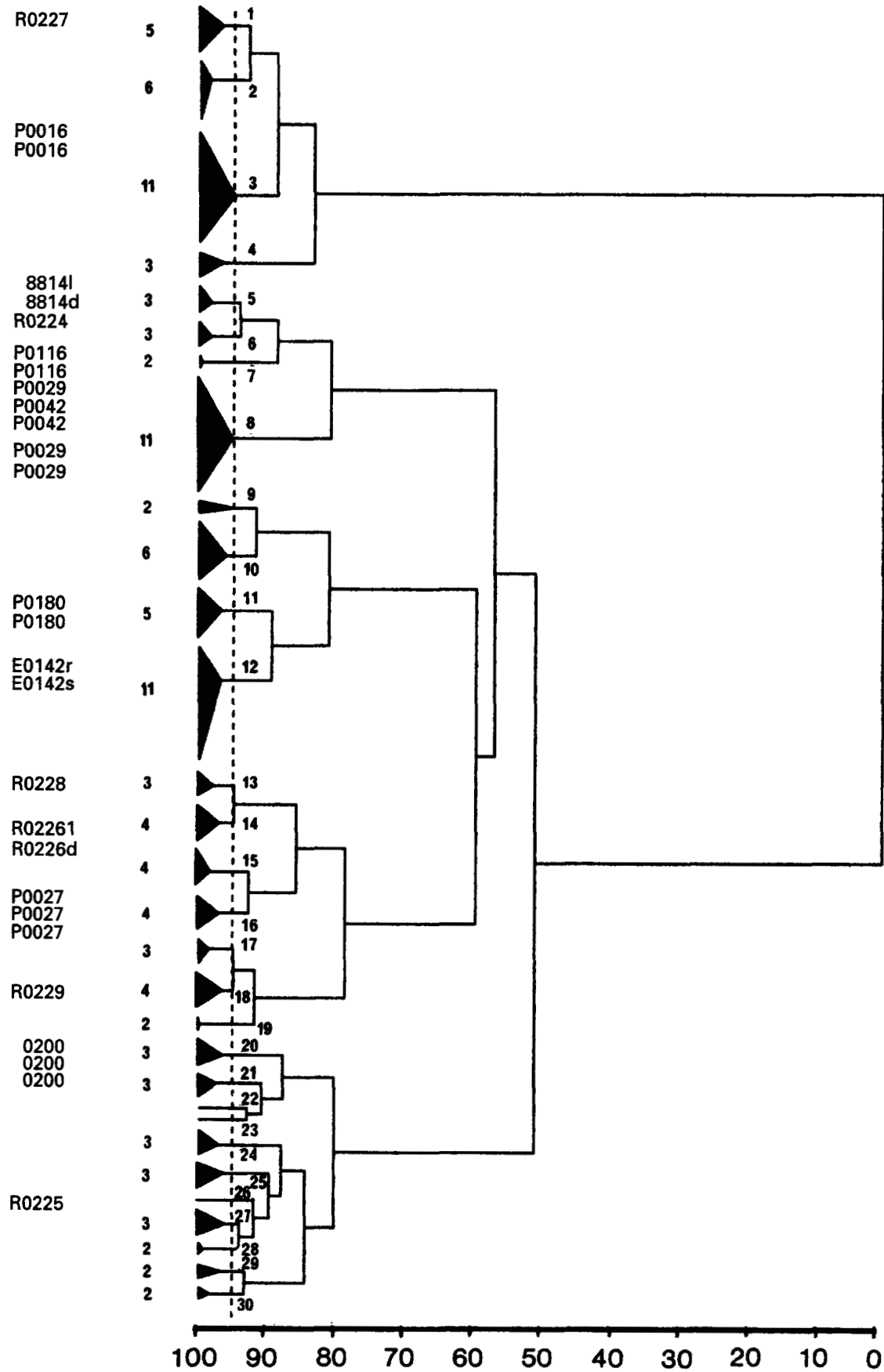

\section{Percentage similarity}

Fig. 2. Dendrogram of all the analysed strains of Aeromonas spp. including deliberate repeats. OTU, operational taxonomic unit, i.e., isolates and replicates. Colonial variants are indicated by strain number and either: 1 and d, light and dark variants or s and r, smooth and rough colony variants.

tracks from these different protein preparations had a mean similarity of 83 (SD6) $\%$, which was the same as that for between-gel comparisons of the same protein preparation. However, changes in culture medium did affect banding patterns. Additional bands in the region 29-14.3 kDa were visible after culture on MacConkey,
CLED or DCA medium, compared to profiles on HBA (results not shown).

When the data were represented as a dendrogram (fig. 2), all the replicate samples and colonial variants clustered at a hierarchical level of $\geqslant 95 \%$. This level defined 30 immunoblot types, of which some examples 


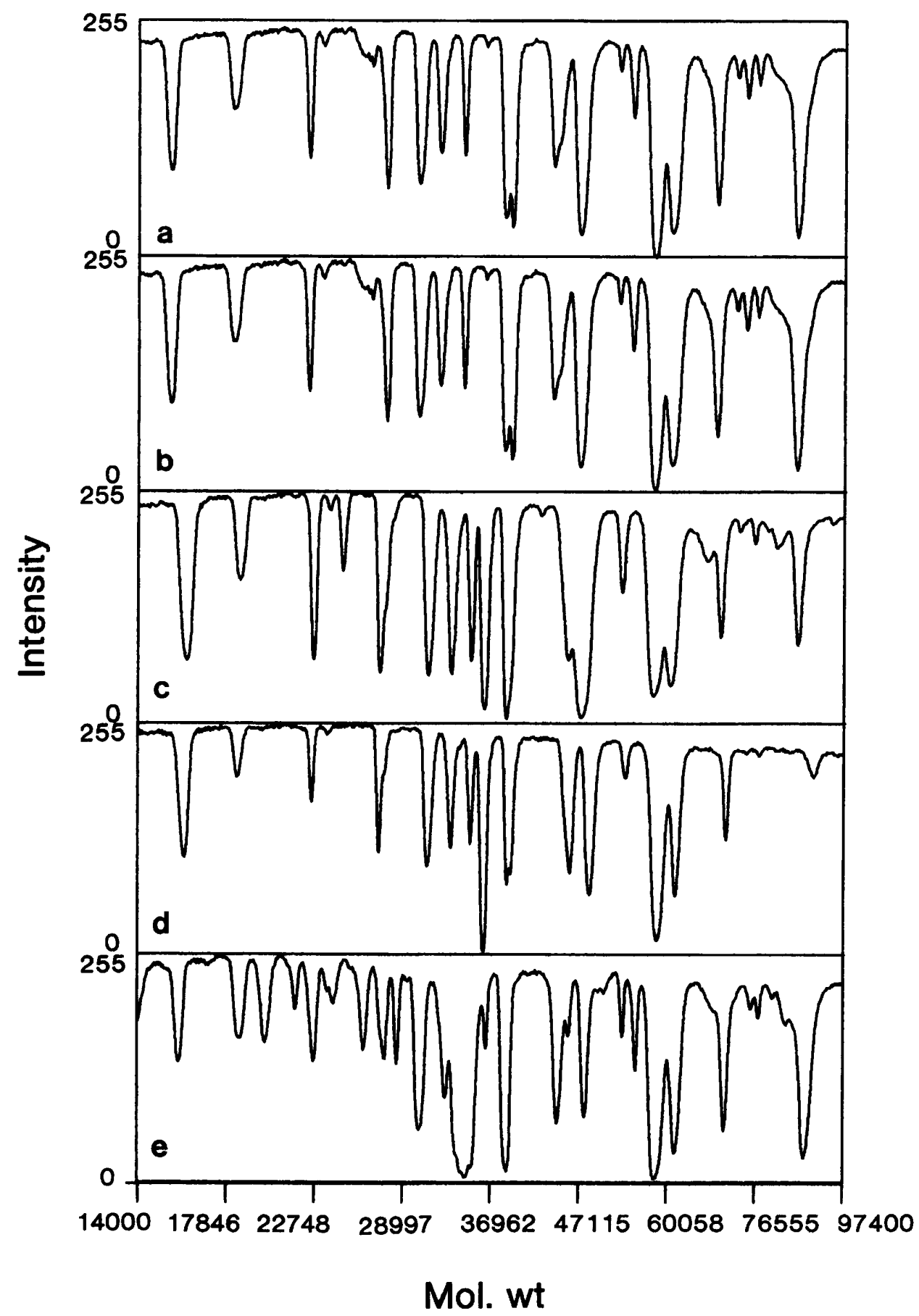

Fig. 3. One-dimensional density plots of the immunoblots of the five Aeromonas strains shown in fig. $1: \mathrm{x}$ axis, linear on scale of $\log _{\mathrm{e}} \mathrm{mol}$. wt (actual weights are shown for clarity); y axis, intensity is in arbitrary units, with 255 indicating maximum brightness. a, Strain E0089, $A$. hydrophila; b, strain E0087, A. hydrophila; $\mathbf{c}$, strain P0042, A. caviae; d, strain P0029, A. caviae; e, strain P0027, A. sobria. Strains E0089 and E0087, and P0042 and P0029 are considered to be the same.

are shown in fig. 3. These plots illustrate the differences between isolates considered to be one strain, and isolates considered to be different strains.

\section{Serology}

Of the 36 strains sent for serotyping, $21(58 \%)$ were non-typable. Among the remaining strains, 12 belonged to one of two serogroups (table).

\section{Clustering}

Immunoblot groups were analysed with regard to serotype, phenotype and epidemiological clustering. Two strains of $A$. caviae in immunoblot groups 2 and 4 were both serogroup AX24 and two strains of $A$. hydrophila in immunoblot group 17 were serogroup 3. Otherwise there was little correspondence between serogroup and immunoblot group. Strains of serogroup O3 were in immunoblot groups $3,10,12,17$ 
Table. Isolates examined by immunoblotting

\begin{tabular}{|c|c|c|c|}
\hline Strain no. & $\begin{array}{l}\text { Species } \\
\text { (Serotype) }\end{array}$ & Source & $\begin{array}{c}\text { Immunoblot } \\
\text { group }\end{array}$ \\
\hline F0168 & Unknown phenotype & Raw chicken & 1 \\
\hline R0227 & A. media & ATCC 33907 & 1 \\
\hline P0149 & A. caviae & Female, 74 years, faeces & 1 \\
\hline E0143 & A. caviae & Kitchen, basement & 1 \\
\hline F0145 & A. caviae & Cockles & 1 \\
\hline P0150 & A. caviae & Male, 17 years, faeces & 2 \\
\hline E0125* & A. caviae (AX24) & Hospital A, tap & 2 \\
\hline E0108 & A. caviae & Hospital A, tap & 2 \\
\hline E0110* & A. caviae (AX24) & Hospital A, storage tank & 2 \\
\hline $\mathrm{E} 0117$ & A. caviae & Hospital B, storage tank & 2 \\
\hline E0120 & A. caviae & Hospital B, storage tank & 2 \\
\hline P0016 & A. caviae & Female, 86 years, faeces & 3 \\
\hline E0090 & A. caviae & Hospital B, storage tank & 3 \\
\hline E0093* & A. caviae & Hospital B, storage tank & 3 \\
\hline E0094* & A. caviae & Hospital B, storage tank & 3 \\
\hline E0096 & A. caviae & Hospital B, storage tank & 3 \\
\hline $\mathrm{E} 0097^{*}$ & A. caviae (AX24) & Hospital B, storage tank & 3 \\
\hline E0119 & A. caviae & Hospital B, storage tank & 3 \\
\hline E0104 & A. caviae & Hospital C, storage tank & 3 \\
\hline E0106* & A. caviae (03) & Hospital C, storage tank & 3 \\
\hline E0088 & A. caviae & Vapour baths & 3 \\
\hline $\mathrm{E} 0082 *$ & A. caviae ( $A X 24$ ) & Hospital A, storage tank & 4 \\
\hline $\mathrm{E} 0083 *$ & A. caviae (AX24) & Hospital A, storage tank & 4 \\
\hline E0095 & A. caviae & Hospital B, storage tank & 4 \\
\hline 8814 & A. caviae & $\begin{array}{l}\text { Maidstone Public Health } \\
\text { Laboratory }\end{array}$ & 5 \\
\hline R0224 & A. caviae & ATCC 13136 & 5 \\
\hline E0176 & Unknown phenotype & Garden puddle & 6 \\
\hline P0170 & A. hydrophila & Male, 80 years, faeces & 6 \\
\hline P0116 & A. caviae & Male, 42 years, faeces & 7 \\
\hline P0131 & A. caviae & Hospital D, ITU, perineal swab & 8 \\
\hline E1322* & A. caviae & Hospital D, ITU, tap & 8 \\
\hline W1326* & A. caviae & Hospital D, ITU, tap & 8 \\
\hline F0134* & A. caviae & Hospital D, ITU, enteral feed & 8 \\
\hline P0029* & A. caviae & Female, 64 years, faeces & 8 \\
\hline P0042 & A. caviae & Female, 83 years, faeces & 8 \\
\hline P0103 & A. caviae & Female, 69 years, faeces & 8 \\
\hline E0113* & A. caviae & Stream, N. Wales & 8 \\
\hline P0156 & A. sobria & Male, 17 years, faeces & 9 \\
\hline P0154 & A. caviae & Male, 16 years, faeces & 9 \\
\hline E0129* & A. caviae & Hospital B, storage tank & 10 \\
\hline P0026* & A. caviae & Male, 1 year, faeces & 10 \\
\hline E0128* & A. caviae & Hospital D, storage tank & 10 \\
\hline P0148 & A. caviae & Female, adult, faeces & 10 \\
\hline $\mathrm{F} 0135^{*}$ & A. hydrophila (03) & Hospital D, ITU, enteral feed & 10 \\
\hline E0163 & A. sobria & Pond & 10 \\
\hline P1801 & Unknown phenotype & Female, adult, wound & 11 \\
\hline E1661 & Unknown phenotype & River Avon & 11 \\
\hline P0179 & Unknown phenotype & Female, 90 years, faeces & 11 \\
\hline E0165 & Unknown phenotype & Pond & 11 \\
\hline $\mathrm{E} 0109 *$ & A. caviae $(A X 24)$ & Hospital B, kitchen tap & 12 \\
\hline $\mathrm{E} 0121^{*}$ & A. caviae (AX23) & Hospital B, storage tap & 12 \\
\hline E0107 & A. caviae & Hospital C, storage tap & 12 \\
\hline P1231* & A. caviae (03) & Hospital D, ITU, throat swab & 12 \\
\hline P1232 & A. caviae & Hospital D, ITU, throat swab & 12 \\
\hline E0111 & A. caviae & Domestic tap & 12 \\
\hline E0142 & A. caviae & Pond & 12 \\
\hline E0112 & A. hydrophila & Stream, N. Wales & 12 \\
\hline E0114 & A. hydrophila & Stream, N. Wales & 12 \\
\hline E0141 & A. hydrophila & Pond & 12 \\
\hline P0169 & A. hydrophila & Female, 54 years, faeces & 13 \\
\hline E0174 & A. caviae & Bath drain & 13 \\
\hline R0228 & A. sobria & ATCC 9071 & 13 \\
\hline P0171 & A. sobria & Female, 74 years, faeces & 14 \\
\hline P0178 & A. sobria & Male, adult, wound & 14 \\
\hline R0226 & A. veronii & ATCC 35622 & 14 \\
\hline E0144* & A. hydrophila & Hospital D, tap & 15 \\
\hline P0139 & A. sobria & Male, 74 years, faeces & 15 \\
\hline P0147 & A. sobria & Male, 71 years, faeces & 15 \\
\hline E0162 & A. sobria & Pond & 15 \\
\hline $\mathrm{P} 0027$ & A. sobria & Male, 80 years, faeces & 16 \\
\hline E0118 & A. sobria & Hospital B, storage tank & 16 \\
\hline E0089* & A. hydrophila (03) & Hospital B, storage tank & 17 \\
\hline
\end{tabular}


Table. (cont.)

\begin{tabular}{cllc}
\hline Strain no. & \multicolumn{1}{c}{$\begin{array}{c}\text { Species } \\
\text { (Serotype) }\end{array}$} & \multicolumn{1}{c}{ Source } & $\begin{array}{c}\text { Immunoblot } \\
\text { group }\end{array}$ \\
\hline & & & \\
E0077* & A. hydrophila (03) & Hospital D, staff residences tap & 17 \\
E0087* & A. hydrophila (016) & Hospital D, staff residences tap & 17 \\
F0130 & A. hydrophila & Hospital D, ITU, enteral feed & 18 \\
$1381^{*}$ & A. hydrophila & Hospital D, ITU, equipment & 18 \\
$1382^{*}$ & A. hydrophila & Hospital D, ITU, equipment & 18 \\
R0229 & A. hydrophila & ATCC 7965 & 18 \\
E0091* & A. hydrophila & Hospital B, storage tank & 19 \\
E0092* & A. hydrophila & Hospital B, storage tank & 19 \\
0200 & Unknown phenotype & Unknown & 20 \\
P0045 & A. sobria & Male, 3 years, faeces & 21 \\
P0051 & A. sobria & Male, adult, faeces & 21 \\
P0074* & A. sobria & Male, adult, faeces & 21 \\
P0084 & A. hydrophila & Female, 21 years, faeces & 22 \\
P0041* & A. hydrophila & Male, 4 months, faeces & 23 \\
P0031* & A. caviae & Female, age unknown, faeces & 24 \\
P0032* & A. caviae & Male, age unknown, faeces & 24 \\
P0048 & A. hydrophila & Male, 4 years, faeces & 24 \\
1140 & A. sobria & Maidstone Public Health & 25 \\
& & Laboratory & 25 \\
E0063 & A. hydrophila & Public baths & 25 \\
E0079* & A. hydrophila & Public baths & 26 \\
R0225 & A. schubertii & ATCC 43700 & 27 \\
E0072 & Unknown phenotype & Hospital E, tap & 27 \\
E0068* & A. hydrophila (03) & Tap water & 27 \\
P0044 & A. caviae & Female, 76 years, faeces & 28 \\
P0043 & A. caviae & Male, 20 years, faeces & 28 \\
E0071 & A. caviae & Tap water & 29 \\
E0028 & A. caviae & Male, 22 years, faeces & 30 \\
E0078 & A. caviae & Hospital E, storage tank & \\
P0055 & A. sobria & Male, 4 years, faeces & \\
P0046* & A. caviae & Female, 3 months, faeces & \\
\hline & & & 29 \\
\hline
\end{tabular}

*Isolates sent to reference laboratory for confirmation of identity and serotyping.

ITU, intensive care unit; $P$, patient ; F, food isolate; $E$, water isolate; $R$, reference strain. All water isolates were from N.E. London unless otherwise stated.

or 27 , and some immunoblot groups $(12,17)$ contained strains of different serotypes. The greater discriminatory capacity of immunoblotting was shown with environmental isolates from hospital A where strains E0082, E0083, E0110, E0125 and E0109 all belonged to serogroup AX24 but were difierentiated into three immunoblot groups.

It also appeared that immunoblot group was independent of phenotype, whether or not newer phenotypes were included. There was no clear segregation of the different phenotypes and some immunoblot groups $(1,6,12,13,14,15,25,27$ and 30) had strains of more than one phenotype.

The epidemiological grouping partially correlated with immunoblot groups (table). Strains E0112 and E0114 isolated from water in N. Wales belonged to immunoblot group 12; strains E0077 and E0087 isolated from staff residences in a N.E. London hospital belonged to immunoblot group 17; strains E0063 and E0079 from public baths in N.E. London belonged to immunoblot group 25 . The majority of isolates from hospital B were in immunoblot group 3, and those from the intensive care unit of hospital $D$ in group 8. However, among the other clusters of environmental isolates only two or three were grouped together by immunoblotting.

\section{Discussion}

All isolates were typable with 15-20 well separated bands, rather than the $30-40$, sometimes overlapping, bands visible in a whole-cell protein fingerprint. Visual analysis of limited numbers of fingerprints was, therefore, simplified. However, all electrophoretic methods have the problem that, unlike conventional typing methods where, for instance, a bacterium either agglutinates with an antiserum or it does not, bands may occur anywhere on an electrophoresis track. Data are produced in analogue rather than digital form, and although similar strains may group together and dissimilar strains appear different, there is no absolute cut-off between them. Therefore, a computer analysis was performed to quantify similarities between isolates.

Results were reproducible, if fingerprints were analysed either within or between gels. It is well known that even with very careful attention to electrophoretic conditions, some allowance must be made for variation in positions of the same band in different gels, ${ }^{32}$ which is usually done by increasing the limits over which a band in different fingerprints is considered to be the same. Although Fourier correlation has several advantages, especially in its tolerance of left and right 
shifts of the whole pattern, increasing the band detection limits cannot be used. Thus to combine within- and between-gel analysis it is necessary to apply a correction factor to the similarity coefficients.

Known replicates clustered at or above the $95 \%$ hierarchical level. At this level, 30 phenons were defined. If phenotype is also considered, the combination with immunoblotting is highly discriminatory. There was partial correlation between immunoblot type and clusters of phenotypically similar isolates from the same source. This is not surprising; a multiplicity of Aeromonas strains in environmental isolates has been described previously. ${ }^{?}$ A number of drinking water isolates were from different hospital buildings which may, at times, have been served by the same reservoir, thus explaining the occurrence of the same immunoblot types in different environmental clusters. There was some evidence that human and environmental strains from the intensive care unit of hospital D were similar. However, none of these strains was isolated from faeces in spite of some of them being found in enteral feeds. There was little evidence that human faecal isolates were acquired from the water supply as in only one case were phenotypically similar isolates of the same immunoblot type isolated from both water and human faeces, despite the probability of some strains being present in the tap water.

It has often been found in other genera that wholecell protein fingerprints are related to phenotype. ${ }^{33}$ However, this does not appear to be the case for aeromonads ${ }^{34}$ or with the immunoblot fingerprints presented here. The finding is not changed by analysis with regard to the newer phenotypes, since no isolates

\section{References}

1. Davis WA, Kane JG, Garagusi VF. Human Aeromonas infections: a review of the literature and a case report of endocarditis. Medicine 1978; 57: 267-277.

2. Segasothy M, Jamal F. Aeromonas hydrophila septicemia in a patient with chronic active hepatitis. Med J Malaysia 1982 ; 37: 211-212.

3. Joseph SW, Daily OP, Hunt WS, Seidler RJ, Allen DA, Colwell RR. Aeromonas primary wound infection of a diver in polluted waters. J Clin Microbiol 1979; 10: 46-49.

4. Qadri SMH, Gordon LP, Weinde RD, Williams RP. Meningitis due to Aeromonas hydrophila. J Clin Microbiol 1976; 3: 102-104.

5. Cookson BD, Houang ET, Lee JV. The use of a biotyping system to investigate an unusual clustering of bacteremias caused by Aeromonas species. J Hosp Infect 1984; 5 205-209.

6. Mellersh AR, Norman P, Smith GH. Aeromonas hydrophila: an outbreak of hospital infection. J Hosp Infect 1984; 5: 425-430.

7. Picard B, Goullet P. Esterase electrophoresis: a new epidemiological screening test for Aeromonas hydrophila hospital infection. $J$ Hosp Infect 1984; 5: 335-336.

8. Gracey M, Burke V, Robinson J. Aeromonas-associated gastroenteritis. Lancet 1982; 2: 1304-1306.

9. Holmberg, Scott D, Farmer JJ. Aeromonas hydrophila and Plesiomonas shigelloides as causes of intestinal infections. Rev Infect Dis 1984; 6: 633-639.

10. Taylor DN, Blaser MJ, Blacklow $\mathrm{N}$ et al. Polymicrobial aetiology of travellers' diarrhoea. Lancet $1985 ; 1$ : 381-383. were thereby redesignated. Although attempts have been made to identify all the known hybridisation groups (HG) phenotypically, ${ }^{35}$ usually the $A$. caviae group (including $A$. media and $A$. eucrenophila) and the $A$. hydrophila group (inducing $A$. salmonicida) are not subdivided. ${ }^{36} A$. veronii ( $A$. veronii biotype veronii) is similar to $A$. hydrophila but cellobiose negative, arginine dihydrolase negative and ornithine decarboxylase positive. $A$. schubertii ferments few sugars but is lysine decarboxylase positive. $A$. trota is similar to $A$. sobria but sucrose negative and ampicillin sensitive. $A$. jandae $i$ is another sucrose-negative species but differentiation from $A$. sobria relies on a very limited number of tests. Therefore, it was not formally included in our analysis; nevertheless, no isolates corresponding to the original description ${ }^{17}$ were found.

Conventional serogrouping was not helpful in identifying clusters of strains because only $42 \%$ were typable and the remainder belonged to a few serotypes. Therefore, we could not make a meaningful comparison with our results. As well as increased typability, the use of antisera for immunoblotting has a further advantage over conventional serological typing in that a single serum source, which does not require cross-adsorption, may be used for all strains.

Our results show that immunoblotting is a useful method for typing Aeromonas spp., with good discrimination and satisfactory reproducibility. Computerised analysis removes the subjective element and between-gel comparisons may be achieved.

R.M. was supported by an Overseas Research Student's Award (ORS award; Association of Principals and Vice-chancellors of the United Kingdom) and a Weston Scholarship (Royal Postgraduate Medical School).

11. Sakazaki R, Shimada T. O-serogrouping scheme for mesophilic Aeromonas strains. Jpn J Med Sci Biol 1984; 37: 247-255.

12. Adams D, Atkinson HM, Woods WH. Aeromonas hydrophila typing scheme based on patterns of agglutination with erythrocyte and yeast cells. J Clin Microbiol 1983; 17: $422-427$.

13. Elbashir AM, Millership SE. Hemagglutinating activity of Aeromonas spp. from different sources; attempted use as a typing system. Epidemiol Infect 1989; 102: 221-229.

14. Stephenson JR, Millership SE, Tabaqchali S. Typing of Aeromonas species by polyacrylamide-gel electrophoresis of radiolabelled cell proteins. $J$ Med Microbiol $1987 ; 24$ : 113-118.

15. Popoff M. Aeromonas. In: Krieg NR, Holt JG (eds) Bergey's Manual of systematic bacteriology, vol. 1. Baltimore, Williams and Wilkins. 1984: 545-548.

16. Carnahan AM, Chakraborty T, Fanning GR et al. Aeromonas trota sp. nov., an ampicillin-susceptible species isolated from clinical specimens. J Clin Microbiol 1991; 29: 1206-1210.

17. Carnahan A, Fanning GR, Joseph SW. Aeromonas jandaei (formerly Genospecies DNA Group 9 A. sobria), a new sucrose-negative species isolated from clinical specimens. $J$ Clin Microbiol 1991; 29 : 560-564.

18. Schubert RH, Hagazi M. Aeromonas eucrenophila species nova Aeromonas caviae, a later and illegitimate synonym of Aeromonas punctata. Zentralbl Bakteriol Mikrobiol Hyg 1988; A268: 34-39.

19. Hickman-Brenner FW, Fanning GR, Arduino MJ, Brenner DJ, Farmer JJ. Aeromonas schubertii, a new mannitol-negative species found in human clinical specimens. J Clin Microbiol $1988 ; 26$ : 1561-1564. 
20. Lee W, Burnie J, Matthews R. Fingerprinting Candida albicans. $J$ Immunol Methods 1986; 93: 177-182.

21. McFarland LV, Mulligan ME, Kwok RYY, Stamm WE. Nosocomial acquisition of Clostridium difficile infection. $N$ Engl J Med 1989; 320: 204-210.

22. Mulligan ME, Kwok RYY, Citron DM, John JF, Smith PB. Immunoblots, antimicrobial resistance, and bacteriophage typing of oxacillin resistant Staphylococcus aureus. J Clin Microbiol 1988; 26 : 2395-2401.

23. Barer MR, Millership SE, Tabaqchali S. Relationship of toxin production to species in the genus Aeromonas. $J$ Med Microbiol 1986; 2: 303-309.

24. Barrit MM. The intensification of the Voges-Proskauer reaction by the addition of $\alpha$-napthol. $J$ Pathol Bacteriol 1936; 42: $441-454$.

25. Scharmann W. Vorkommen von Elastase bei Pseudomonas und Aeromonas. Zentralbl Bakteriol 1972; A220: 435-442.

26. Møller V. Activity determination of amino acid decarboxylases in Enterobacteriaceae. APMIS 1954; 34: 102-114.

27. Hickman-Brenner FW, MacDonald KL, Steigerwt AG, Fanning GR, Brenner DJ, Farmer JJ. Aeromonas veronii, a new ornithine decarboxylase-positive species that may cause diarrhea. J Clin Microbiol 1987; 25: 900-906.

28. Lowry OH, Rosebrough CS, Randall RJ. Protein measurement with the folin phenol reagent. $J$ Biol Chem 1951; 193: 265-275.

29. Laemmli UK. Cleavage of structural proteins during the assembly of the head of bacteriophage T4. Nature 1970; 227: $680-685$.

30. Millership SE, Ragoonaden K. Automated lanes detection and comparison of bacterial electrophoretic protein fingerprints using fast Fourier transformation. Comput Biomed Res 1992; 25 : 392-406.

31. Gordon AD. Classification. London, Chapman and Hall. 1981 : 41-42.

32. Plikaytis BD, Carlone GM, Plikaytis BB. Numerical analysis of normalized whole-cell protein profiles after sodium dodecyl sulphate-polyacrylamide gel electrophoresis. J Gen Microbiol 1986; 132: 2653-2660.

33. Kersters K. Numerical methods in the classification of bacteria by protein synthesis. In: Goodfellow M, Jones D, Preist FG (eds) Computer assisted bacterial systematics. London, Academic Press. 1985: 337-368.

34. Millership SE, Want SV. Characterisation of strains of Aeromonas spp. by phenotype and whole protein fingerprint. J Med Microbiol 1993; 39: 107-113.

35. Abbot SL, Cheung WKW, Kroske-Bystrom S, Malekzadeh T, Janda JM. Identification of Aeromonas strains to genospecies level in the clinical laboratory. J Clin Microbiol 1992; 30: 1262-1266.

36. Janda JM. Recent advances in the study of the taxonomy, pathogenicity and infectious syndromes associated with the genus Aeromonas. Clin Microbiol Rev 1991; 4: 397-410. 